\title{
Eye Drops Solvent for Reconstitution Dosage Form
}

National Cancer Institute

\section{Source}

National Cancer Institute. Eye Drops Solvent for Reconstitution Dosage Form. NCI

Thesaurus. Code C149507.

Liquid preparation consisting of a sterile solvent containing no active substances,

intended for reconstitution of a usually freeze-dried powder for eye drops. 